\title{
O emprego de resíduos de areia de fundição (RAF) em concreto asfáltico: uma alternativa para a sustentabilidade na pavimentação
}

\author{
The use of residues of foundry sand (RFS) in \\ asphalt concrete: an alternative for \\ sustainability in paving
}

Paulo Paiva Oliveira Leite Dyer ${ }^{1}$, Luis Miguel Gutierrez Klinsky ${ }^{2}$, Silvelene Alessandra Silva ${ }^{3}$, Maryangela Geimba de Lima ${ }^{4}$

\footnotetext{
${ }^{1}$ Laboratório de Infraestrutura Aeroportuária - EIA/ITA, CEP: 12228-900, São José dos Campos, SP, Brasil.

${ }^{2}$ Laboratório de pesquisas rodoviárias - CPR/CCR Nova Dutra - CEP:12364-61223, Santa Izabel, SP, Brasil.

${ }^{3}$ Laboratório de Fotônica - EFO/IEAv, CEP: 12228-001, São José dos Campos, SP, Brasil.

${ }^{4}$ Laboratório de Infraestrutura Aeroportuária - EIA/ITA, CEP: 12228-900, São José dos Campos, SP, Brasil.

e-mail:paulo_dyer@yahoo.com.br, luis.gutierrez@grupoccr.com.br, lenisoni@uol.com.br, magdlima@gmail.com
}

\begin{abstract}
RESUMO
Neste artigo, resíduos de areias de fundição (RAFs) originários de: escavação em aterro sanitário industrial e diretamente de indústrias siderúrgicas automotivas foram testados como agregado em misturas asfálticas à quente. Estes RAFs, juntamente com o agregado miúdo convencional, foram caracterizados fisicamente obtendo no ensaio de: material pulverulento, teores inferiores a 13\%; composição granulométrica, curvas de material passante em função da abertura das malhas equivalentes ao agregado miúdo (segundo a norma de agregados); densidade real, aparente e saturada muito próximas ao agregado mineral; micrografia óptica, imagens ampliadas (de 10 e 40 vezes obtidas em um Estereoscópio óptico) das frações representativas do maior e menor tamanhos de grãos, visualmente uniformes e semelhantes entre si. Em seguida, foram elaboradas formulações de misturas de agregados e RAFs contendo teores de substituição dos resíduos de: 0\% (mistura Controle), 50 e $100 \%$ em relação ao pó de pedra e moldados corpos de prova cilíndricos pelo método giratório SUPERPAVE com cimento asfáltico do tipo CAP 30/45. Estes CPs foram testados no ensaio de tração por compressão diametral, obtendo valores de resistência a tração (RT) da ordem de: 2,0 MPa, para as misturas contendo 50\% de RAF (das duas origens) e da ordem de 1,3 MPa nas misturas contendo $100 \%$ de RAF; e ensaio de módulo de resiliência obtendo valores médios da ordem de: 2500 a $6000 \mathrm{MPa}$. Concluiu-se que o RAF possui viabilidade técnica como agregado em pavimentos flexíveis.
\end{abstract}

Palavras-chave: resíduos, sustentabilidade, pavimentos.

\section{ABSTRACT}

In this paper, residues of foundry sand (RFS) originating from: excavation in industrial landfill and from automotive steel industries were tested as aggregate in hot mix asphalt mixtures. These RFS together with the conventional aggregate were physically characterized at the assays: pulverulent material content by weight, obtaining less than $13 \%$; sieve analysis determined the fine granulometry of these materials (according to the aggregate standard); real, apparent and saturated density very close to the mineral aggregate; and the applied images (10 and 40-fold) obtained in an optical stereoscope of the representative fractions of larger and smaller grain sizes, determined a visually uniform and similar between the materials. Then, were made formulations of mixtures of aggregates and RFS, were substitution of the manufactured sand by the residues of $0 \%$ (Control mixture), 50 and $100 \%$ in weight and were molded cylindrical specimens (CS) by gyratory compaction method, with asphalt binder type CAP 30/45. These CS were tested in the splitting tensile strength assay obtaining values of tensile strength (TS) of the order of 2,0 MPa, for mixtures containing $50 \%$ of RFS and of 
the order of 1,3 MPa in mixtures containing 100\% RFS (of two origins); and test of resilience module obtaining average values of the order of: 2500 to $6000 \mathrm{MPa}$. It was concluded that the RFS has technical viability as an aggregate in flexible pavements.

Keywords: waste, sustainability, pavements.

\section{INTRODUÇÃO}

O modelo de desenvolvimento sustentável surgiu como uma medida para evitar futura escassez de recursos e desiquilíbrios climáticos devido ao desenvolvimento sem controle. Este conceito evoluiu a partir de conferências mundiais, acordos e termos de responsabilidade e atualmente possui diversas ramificações, sendo aplicado em vários setores industriais [1]. Uma destas vertentes refere-se à sustentabilidade na construção civil, uma vez que o ambiente urbano gera impactos de forma significativa ao meio ambiente e sociedade [2]. A sustentabilidade surgiu neste setor com o objetivo de reduzir desperdícios e a pegada ambiental, criando métodos inovadores e uma maior integração entre empreendimentos e meio ambiente [3]. Tal modelo vem crescendo atualmente, desta forma é cada vez maior a demanda por métodos construtivos mais econômicos e materiais de construção inovadores.

Neste cenário, a problemática dos resíduos também se torna crescente. Os resíduos industriais que são produzidos de forma periódica, em grandes volumes e que não são considerados perigosos como os de Classificação II, tais como os Resíduos de Areias de Fundição - RAFs gerados pelas indústrias de fundição, representam um problema de desperdício financeiro, uma vez que, requerem grandes espaços para armazenagem [4], esgotando as capacidades dos aterros sanitários de uma forma mais rápida.

Devido a estes resíduos possuírem aspectos físicos químicos similares aos agregados utilizados na construção civil [5], cria-se uma oportunidade em utiliza-los para este fim. Desenvolvendo métodos construtivos mais econômicos, além de gerar benefícios aos setores industriais impactados [5 -7].

Entidades de pesquisa vêm a muito desenvolvendo sistemáticas para incorporar este resíduo na construção civil, como a pavimentação asfáltica [5,8], porém novos estudos ainda são necessários para enquadrar esta metodologia no mercado da construção civil e normas regulamentadoras [9].

\section{FUNDAMENTAÇÃO TEÓRICA}

\subsection{A sustentabilidade na construção civil}

A sustentabilidade na construção civil é um modelo de desenvolvimento que visa integrar conceitos de educação socioambiental aos projetos de construção civil, seja na fase de construção, ocupação e pós-construção (reformas e demolição) utilizando de novas tecnologias que não prejudiquem características de designe e conforto, atendendo as exigências dos usuários de maneira eficiente, ou seja, evitando desperdícios e reduzindo impactos ambientais [1]. Este modelo, uma das vertentes do conceito de sustentabilidade, se preocupa com a eficiência de um empreendimento e com o impacto ambiental que um ambiente urbano gera tanto para o meio ambiente, quanto para a sociedade.

De acordo com o CONSELHO BRASILEIRO DE CONSTRUÇÃO SUSTENTÁVEL, criado em agosto de 2007 [10], o setor da construção necessita ser induzido a utilizar práticas mais sustentáveis, uma vez que, se trata do ramo que mais emprega no Brasil também é um dos maiores produtores de resíduos, neste contexto é imprescindível a demanda por empresas que tomem algumas medidas para inverter os atuais papéis exercidos pela construção civil no contexto ambiental. Assim sendo, uma construção sustentável é aquela que utiliza materiais e tecnologias bio-compatíveis a fim de reduzir o impacto ambiental durante o processo de obtenção, fabricação, aplicação e em toda a sua vida útil. Porém o grande entrave para a consolidação desta "visão sustentável" no setor de construção civil é a dificuldade em relação aos custos considerados elevados de determinados elementos que permitem o enquadramento do empreendimento nesse conceito.

\subsection{Resíduo de areias de fundição e contexto}

Como na construção as indústrias siderúrgicas são segmentos de mercado de grande importância econômica no Brasil e no mundo [11], estes empreendimentos são responsáveis pela produção de peças metálicas utilizadas em diversas cadeias industriais, tendo como maior destaque a automotiva. Segundo os relatórios mensais de 2018, elaborados pela ASSOCIAÇÃO BRASILEIRA DE INDÚSTRIAS DE FUNDIÇÃO (2018) [11], até o mês de setembro de 2018, foi produzido um total de 1,7 milhões de toneladas de peças fundidas no Brasil [11], concentrando esta produção nas regiões Sudeste e Sul do país. 
O processo de fundição utilizando areias minerais finas como fôrmas para peças metálicas é composto pelas seguintes etapas básicas: primeiramente em uma caixa quadrada de contenção é posicionada uma peça protótipo previamente fabricada, constituída de cera, resina ou algum material volátil à temperatura de fusão do metal; em seguida os espaços vazios entre a peça protótipo e a caixa de contenção são preenchidos por uma areia mineral muito fina (grãos menores que $0,10 \mathrm{~mm}$ ) saturada de aglutinantes como água, ácidos graxos, óleos minerais, entre outros; o conjunto areia e protótipo são vibro-compactados; o metal derretido a ser trabalhado é despejado sob a peça protótipo volatilizando-a; o conjunto todo esfria e o metal se torna rígido; e então o molde é quebrado e a peça metálica é obtida [11], como ilustrado na figura 1.
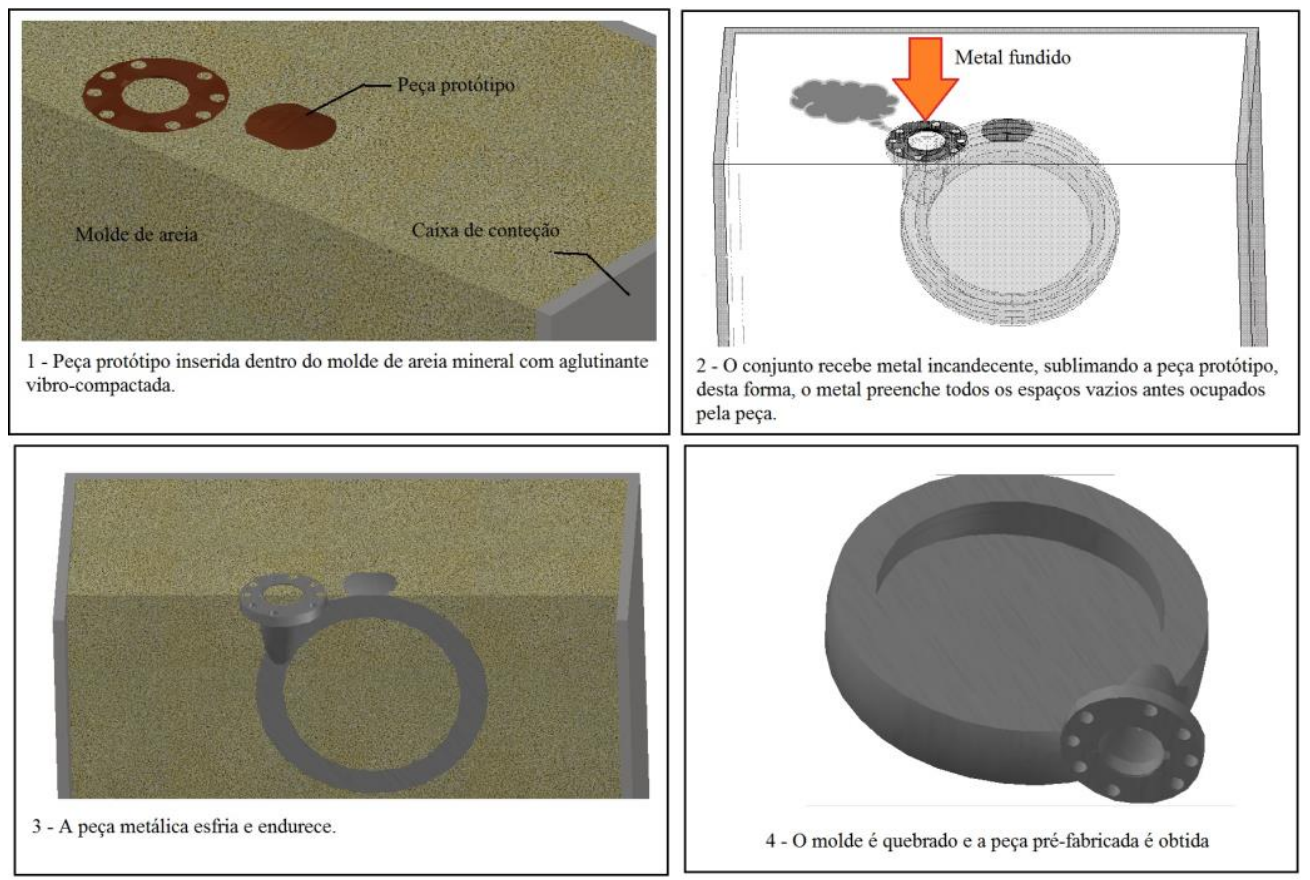

Figura 1: Processo simplificado de fundição.

Os processos de fundição se dividem quanto ao tipo de aglutinante utilizado, que podem ser materiais hidrofóbicos ou hidrofílicos:

1. Areia verde: areias minerais moldadas no formato do molde da peça em estado úmido, ou seja, saturadas com água mantendo a coesão entre os grãos;

2. Alcalino fenólica: areias minerais moldadas no formato do molde da peça saturada por uma resina fenólica e depois curada a quente com catalisador [12];

3. Fenólico uretânica: areias moldadas saturadas com resinas fenólicas uretânicas e curadas a frio com catalisador [13];

4. Furânica: similar ao método alcalino fenólico, porém com resina Furânica [14,15];

5. Shell ou "Shell mouding": é realizada a mistura entre uma resina termo fixa, areia mineral e catalisador, a areia á colocada na caixa de contenção, o conjunto é vibrado juntamente com a peça protótipo, é formada uma casca na superfície do negativo, a areia não curada é removida e então a casca é removida $[14,15]$;

6. Silicato de sódio: é feita a mistura da areia mineral com silicato de sódio, o conjunto é vibro compactado no formato do negativo da peça e a mistura é gaseificada com gás carbono formando pontes químicas entre os grãos [16].

De modo geral, é desta forma que se dá tal processo, podendo variar quanto à qualidade exigida pelo ciente, como em peças ocas, as quais necessitam de "machos" internos constituintes de areias aglutinadas quimicamente por bentonita, porém a característica comum deste processo é sua simplicidade. De acordo com BONET (2002) [9], após sua utilização a areia pode ser recuperada, uma vez que, passe por um tratamento mecânico por peneiramento, para remoção de partículas aglutinadas e um tratamento térmico para remoção de resinas e óleos, tal processo aumenta a vida útil da areia no sistema de fundição, porém ainda são produzidos cerca de 600,00 kg de RAF, de acordo com BINA (2002) [4], para cada tonelada de peça metálica 
produzida. Uma quantidade que representaria mais de 1 milhão de toneladas para a produção brasileira de 9 meses no ano de 2018 [11]; sendo então um resíduo que desperta preocupação pelo volume produzido e a capacidade dos aterros sanitários em estar recebendo toda esta quantidade.

\subsection{Classificação do Resíduo de Areia de Fundição}

O RAF foi classificado a partir da decisão de Diretoria No 152/2007/C/E, de 08 de agosto de 2007 da COMPANHIA DE TECNOLOGIA DE SANEAMENTO AMBIENTAL (2007) do Estado de São Paulo; classificando-o como um resíduo sólido industrial de classe II-A ou II-B, sendo que para a classificação II-A este RAF se enquadra como não perigoso e não inerte e II-B se enquadra como inerte, o enquadramento adequado dependera das características químicas deste material que variam de acordo com sua origem, tais resultados podem ser obtidos em análises laboratoriais.

Resíduos não inertes são quaisquer resíduos que não tiverem nenhum de seus constituintes solubilizados a concentrações superiores aos padrões de potabilidade de água, excetuando-se aspecto, cor, turbidez, dureza e sabor, conforme anexo G da ASSOCIAÇÃO BRASILEIRA DE NORMAS TÉCNICAS (ABNT) para a NORMA REGULADORA NBR:10004/2004 [18] e lixiviados a concentrações superiores ao anexo F desta mesma NBR (2004), não apresentando risco agudo a saúde humana. Porém, segundo BONIN (1995) [19], este tipo de resíduo não pode ser alocado em lugares inadequados, uma vez que com o despejo frequente, as concentrações de substâncias nocivas presentes no RAF aumentam ao longo do tempo atingindo níveis perigosos podendo contaminar solo e água no entorno deste despejo. Desta forma o aterramento do RAF é a medida mais adotada pela siderurgia, um procedimento que além de oneroso às indústrias e que diminui rapidamente a vida útil dos aterros sanitários devidos aos elevados volumes produzidos [11], é um procedimento que traz menos prejuízos à saúde humana e meio ambiente; lembrando que, apenas indústrias de grande porte tomam estes cuidados [5], todavia as pequenas e médias indústrias, em sua maioria, praticam o despejo ilegal do resíduo em lixões, terrenos baldios, entre outros; produzindo uma externalidade socioambiental que poderá impactar gerações futuras e destruir fauna e flora locais [17,19].

\subsection{Usos de RAF na construção civil}

Portanto, devido aos malefícios financeiros e socioambientais que a produção deste subproduto gera e visto que, por representar um motivador à economia nacional, não podendo cessar tal aditividade industrial, são encontradas na literatura muitas formas de reutilização do RAF pela construção civil, uma vez que este material apresenta características físicas químicas semelhantes aos agregados finos amplamente utilizados em argamassas hidráulicas, argamassas betuminosas e composição solos. A tabela 1 apresenta um resumo dos usos na construção civil de RAF por diversos pesquisadores e entidades de pesquisa [8].

Desta forma, diversas universidades em todo o mundo desprendem esforços sistemáticos para o estudo da destinação do resíduo de areia pelas fundições para vários usos fora da atividade de fundição [8]. Para BONET (2002) [9] as aplicações fora das fundições incluem o emprego da areia usada proveniente de fundições para: fonte de sílica na produção do clinker ou de lãs minerais; substituto parcial do agregado fino em concreto de baixo custo para aplicações não estruturais e artefatos de concreto; agregado fino para concreto asfáltico na pavimentação flexível; fonte de minerais para ajuste de solos na agricultura; e misturas de solos em subleitos e aterros. Quanto à aplicação na produção de clinker o processo é viável tecnicamente, porém as fontes geradoras e consumidoras deverão estar próximas devido ao custo de transporte, sendo que, nas demais aplicações BONET (1995) [9] considera que existem resultados tecnologicamente aceitáveis em todas elas, embora haja ainda muito trabalho de desenvolvimento a ser feito, inclusive no que diz respeito à avaliação do comportamento desses materiais em longo prazo, em particular, para que a areia de fundição venha a ser admitida como substituto parcial de agregado miúdo haverá necessidade de mais estudos sistemáticos, como a caracterização, segundo norma brasileira de agregados ABNT-NBR:7211/2005 [20], que poderão levar a adaptações nas normas vigentes em construção civil.

De acordo com SINGH et. al. (2012) [21], os concretos de cimento Portland contendo 15\% de RAF, em relação aos agregados convencionais, obtiveram ganhos de resistência mecânica, em relação à concretos convencionais na ordem de $20 \%$, porém em quantidades maiores, como $20 \%$, foram observadas perdas de qualidade; mas, como o autor observou, tais concretos poderiam ser utilizados na produção de materiais de construção sem função estrutural, como calçadas para pedestres, tijolos para construção de canteiros, entre outros. Este resultado foi corroborado por MYNUDDIN et. al. (2018) e ANDRADE et al. (2018) [22, 5] que observaram poucas alterações do concreto contendo 10 a $30 \%$ de ADF, em relação à areia mineral, considerando a resistência à compressão.

Em projetos de pavimentação asfáltica, YAZOGHLI-MARZOUK et al. (2014) [23] determinou como 
aceitáveis para camadas de sub-base compostas de RAF tratada com 6\% de ligante hidráulico (como cimento Portland), compondo um material de características semelhantes à um solo-cimento. KLINSKY (2013) [24] por sua vez, realizou um estudo deste resíduo incorporado em camadas de base composta por um latossolo tratado com $7 \%$ de cimento Portland, observando valores coerentes com materiais convencionais em ensaios mecânicos de índice de suporte Califórnia (CBR). Já para camada de revestimento, seu emprego foi estudado por COUTINHO (2004) [25] em misturas de concreto asfáltico, também conhecido como deep strength asphalt pavement que são revestimentos espessos desdobrados em diversas subseções, obtendo resultados satisfatórios em ensaios mecânicos (segundo as normas da engenharia rodoviária) e de durabilidade deste concreto (ensaios de dano por umidade induzida); em seu trabalho foi adotado o limite de $15 \%$ de substituição de RAF, em relação ao pó de pedra.

Tabela 1: Aplicações do RAF na construção civil. Adaptado de TCDC (1999) [8].

\begin{tabular}{|c|c|c|c|c|c|c|c|}
\hline \multicolumn{2}{|c|}{ APLICAÇÕES DE REUSO } & \multicolumn{6}{|l|}{ ADF } \\
\hline Uso & a construção & 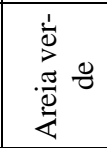 & 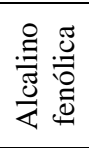 & 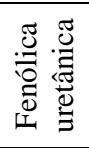 & 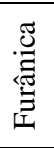 & $\sum_{\frac{\Sigma}{\infty}}^{\frac{1}{0}}: \stackrel{0}{=}$ & 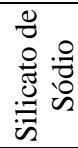 \\
\hline \multicolumn{2}{|c|}{ Asfalto } & $\mathrm{X}$ & $\mathrm{X}$ & $*$ & $*$ & $*$ & 0 \\
\hline \multicolumn{2}{|c|}{ Produção de blocos } & $*$ & $*$ & $*$ & $*$ & $\mathrm{X}$ & $*$ \\
\hline \multicolumn{2}{|c|}{ Produção de tijolos } & $X$ & $\mathrm{X}$ & $*$ & $*$ & $*$ & $\mathrm{~S}$ \\
\hline \multicolumn{2}{|c|}{ Cimento } & $\mathrm{X}$ & $\mathrm{X}$ & $*$ & 0 & $\mathrm{X}$ & $X$ \\
\hline \multicolumn{2}{|c|}{ Concreto } & $\mathrm{S}$ & $\mathrm{X}$ & $*$ & $*$ & $*$ & $*$ \\
\hline \multicolumn{2}{|c|}{ Substituto de agregados finos } & $\mathrm{X}$ & $X$ & $*$ & $*$ & $*$ & $*$ \\
\hline \multicolumn{2}{|c|}{ Concreto expandido } & $X$ & $\mathrm{X}$ & $*$ & $S$ & S & $\mathrm{S}$ \\
\hline \multicolumn{2}{|c|}{ Produção de argamassa } & $\mathrm{S}$ & $\mathrm{S}$ & $\mathrm{S}$ & $S$ & $\mathrm{~S}$ & $*$ \\
\hline \multicolumn{2}{|c|}{ Construção de base de estradas } & $\mathrm{S}$ & $\mathrm{X}$ & $*$ & $S$ & $*$ & $\mathrm{X}$ \\
\hline \multicolumn{2}{|c|}{ Camadas artificiais de topo de solos } & $X$ & $*$ & $*$ & $X$ & $*$ & $\mathrm{~S}$ \\
\hline \multicolumn{2}{|c|}{ Cobertura de aterros } & $X$ & $X$ & $*$ & $S$ & $S$ & $\mathrm{~S}$ \\
\hline \multicolumn{2}{|c|}{ Modificador de solos } & $*$ & $*$ & $*$ & $*$ & $*$ & $*$ \\
\hline \multicolumn{2}{|c|}{ Fabricação de cimento } & $\mathrm{S}$ & $\mathrm{S}$ & $\mathrm{S}$ & $S$ & $\mathrm{~S}$ & $*$ \\
\hline \multicolumn{8}{|c|}{ Legenda } \\
\hline $\mathrm{X}$ & \multicolumn{7}{|c|}{ Aplicação de reuso aprovada, com projetos já implantados na Inglaterra. } \\
\hline * & \multicolumn{7}{|c|}{ Aplicação teórica, mas não existem projetos de reuso operando na Inglaterra. } \\
\hline 0 & \multicolumn{7}{|c|}{ Inadequado para reuso na forma não tratada. } \\
\hline $\mathrm{S}$ & \multicolumn{7}{|c|}{ Sem referência de estudos ou aplicações } \\
\hline
\end{tabular}

Assim é observado que os resíduos de areias de fundição apresentam grande potencial de reuso como agregado em construção civil, tal procedimento poderia gerar materiais de construção com custos inferiores aos encontrados no mercado, em especial na pavimentação asfáltica, uma vez que tais empreendimentos são grandes consumidores de agregados minerais gerando uma sustentabilidade maior à obra

\section{MATERIAIS E MÉTODOS}

\subsection{Materiais}

Para determinar a viabilidade da utilização de RAF em CBUQ para pavimentação flexível, foram utilizados os seguintes materiais: 
- RAF originário de aterro: em um aterro sanitário industrial, o RAF se encontrava aterrado sobre uma camada de três metros de solo compactado, há mais de 30 anos. Este RAF era originário de uma indústria automotiva nos arredores da região de São José dos Campos - São Paulo, onde se localiza o mesmo aterro sanitário industrial, este material será identificado pela sigla: RAF-1;

- RAF originário de indústria siderúrgica: neste mesmo aterro sanitário, onde foi escavado o RAF-1, foram coletadas amostras de RAF originário de indústrias siderúrgicas da região onde se localiza o aterro, uma vez que o mesmo ainda recebe este tipo de resíduo. Aqui, este material será identificado pela sigla: RAF-2;

- Agregados minerais: pó de pedra, brita-0 e brita-1, todos originários de uma pedreira de rocha granítica localizada na idade de Jambeiro, São Paulo;

- Aditivo mineral ou filler: constituído de cal hidratada $(\mathrm{Ca}(\mathrm{OH}) 2)$, adquirido de represente comercial do Estado de São Paulo;

- Ligante asfáltico do tipo CAP 30/45: adquirido da Revap;

- Água deionizada: obtida do processo de de-ionização da água.

\subsection{Métodos}

Inicialmente foi executada uma amostragem de resíduos sólidos para o RAF 1 e 2 de acordo com a norma brasileira de amostragem de resíduos sólidos ABNT-NBR:10007/200 [26], a qual determina que sejam retiradas porções diametralmente opostas de uma pilha de resíduos até atingir a quantidade desejada, no caso $150 \mathrm{~kg}$ foram amostrados para cada RAF. O RAF que se encontrava aterrado foi retirado realizando uma escavação de três metros de profundidade em um local ao acaso no aterro sanitário, e então executada um peneiramento prévio obtendo uma pilha com diâmetro máximo dos grãos de $12,7 \mathrm{~mm}$, ilustrado na figura 2.

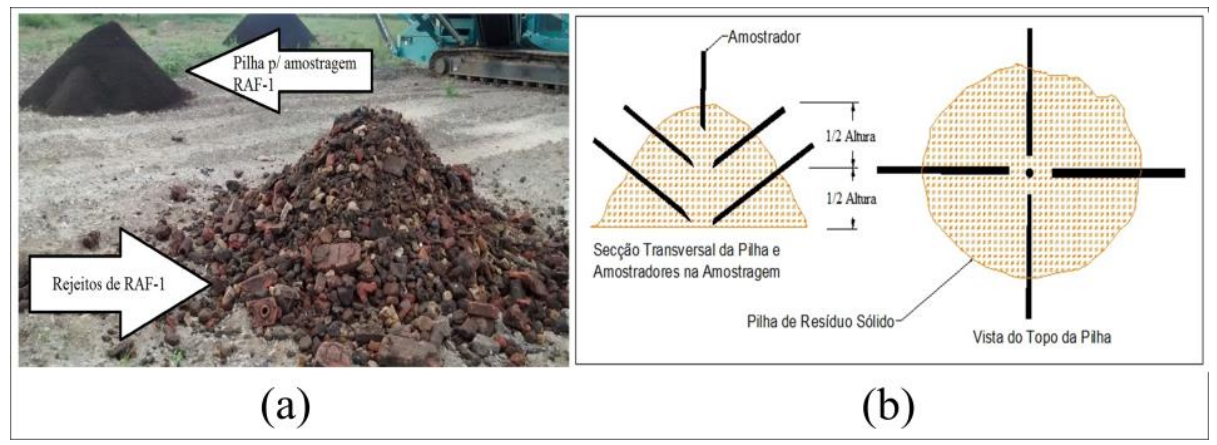

Figura 2: Fotografias e procedimento de amostragem de RAF-1 onde (a) é a pilha formada após o peneiramento prévio e (b) se trata do esquema para amostragem, fonte: NBR:10007/2004 [26].

No caso do RAF-2, foi escolhida uma caçamba de coleta do aterro sanitário (figura 3) e repetido o procedimento de amostragem, executando-se o peneiramento prévio, uma vez que estes RAF in natura possuíam muitos detritos originários do processo de fundição como pedaços de metais, sílicas aglutinadas, machos de bentonita, entre outros.

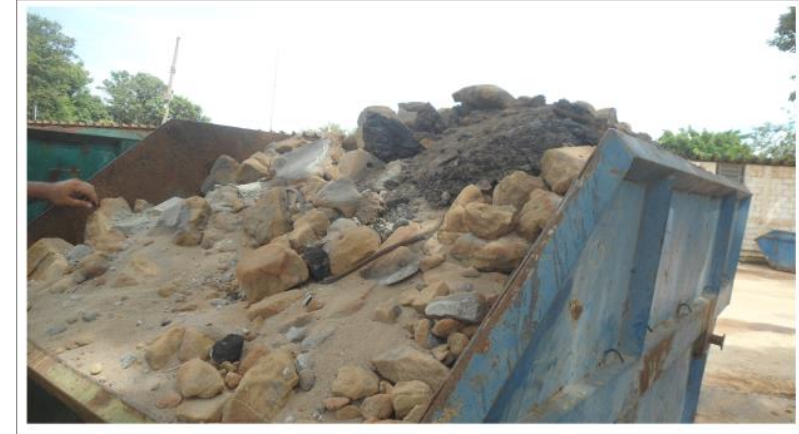

(a)

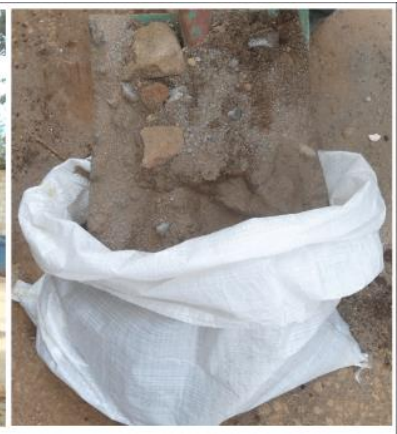

(b)

Figura 3: Fotografias do procedimento de amostragem de RAF-2, onde em (a) o RAF se encontrava na caçamba e em (b) o RAF estava sendo amostrado. 
Os demais agregados foram amostrados de acordo com a norma brasileira de amostragem de agregados minerais ABNT NBR NM:26/2001 [27], recolhidos em quantidades análogas ao RAF nas instalações da pedreira. Para produzir amostras nas quantidades adequadas para cada ensaio realizado posteriormente, foi adotado o procedimento de redução de amostras por quarteamento mecânico, determinado pela norma brasileira ABNT-NBR-NM:27/2001. E assim com todas as amostras de cada material utilizado, foram realizados os ensaios apresentados na tabela 2. Já o fluxograma da figura 4, determina a ordem de cada ensaio.

Tabela 2: Ensaios realizados de acordo com a norma de método de ensaio e material utilizado.

\begin{tabular}{|c|c|c|}
\hline MATERIAIS & MÉTODO DE ENSAIO & ENSAIO \\
\hline RAFs & NBR:10007/2004 [26] & Amostragem \\
\hline Agregados & NBR-NM:26/2001 [27] & Amostragem \\
\hline Agregados e RAFs & NBR-NM:27/2001 [28] & Redução de amostras \\
\hline Agregados e RAFs & NBR-NM:46/2003 [29] & Material pulverulento \\
\hline Agregados e RAFs & NBR:248/2003 [30] & Granulometria \\
\hline Agregados e RAFs & NBR-NM 45/2006 [31] & Massa unitária \\
\hline Agregados e RAFs & NBR-NM:52/2009 e 53/2003 [32, 33] & Densidade real, aparente e saturada \\
\hline Aditivo mineral & NBR-NM:23/2001 [34] & Densidade real do filler mineral \\
\hline Agregados e RAFs & NBR-NM: 30/2001 e 53/2003 [35, 33] & Absorção de água \\
\hline CAP $30 / 45$ & NBR:14541/2014 [36] & Viscosidade Brookfield \\
\hline CAP $30 / 45$ & DNIT-ME:155/2010 [37] & Penetração de betume \\
\hline Pó de pedra e RAFs & Sem norma & Microscopia óptica \\
\hline Agregados, RAFs, CAP 30/45 e filler & DNIT-ES:031/2006 [38] & Doságem Marshall \\
\hline Agregados, RAFs, CAP 30/45 e filler & ASTM D 2041 M-11/2011 [39] & Mistura giratória SUPERPAVE \\
\hline Misturas asfálticas & AASHTO PP 60-14/2014 [40] & Compactação giratória SUPERPAVE \\
\hline CPs & DNIT-ME:136/2017 [41] & Resistencia à tração \\
\hline CPs & DNIT-ME:135/2010 [42] & Módulo de resiliência \\
\hline
\end{tabular}

Durante os ensaios preliminares de caracterização [29-35], foram conhecidas as propriedades dos materias agregados e RAFs segundo os critérios da norma de agregados minerais [20]. O ligante asfáltico (CAP 30/45) também foi caracterizado, determinando suas propriedades de temperatura de mistura e compactação [36], bem como a compatibilidade técnica da especificação 30/45 do fabricante com suas propriedades físicas reais determinadas em ensaio [37].

Na etapa de obtenção de ampliações em alta definição com um estereoscópio óptico, RAF e pó de pedra foram visualizados nas faixas granulométricas representativas de maior e menor diâmetro dos grãos (definidos no ensaio de granulometria) em aumentos específicos, como definido na tabela 3. 


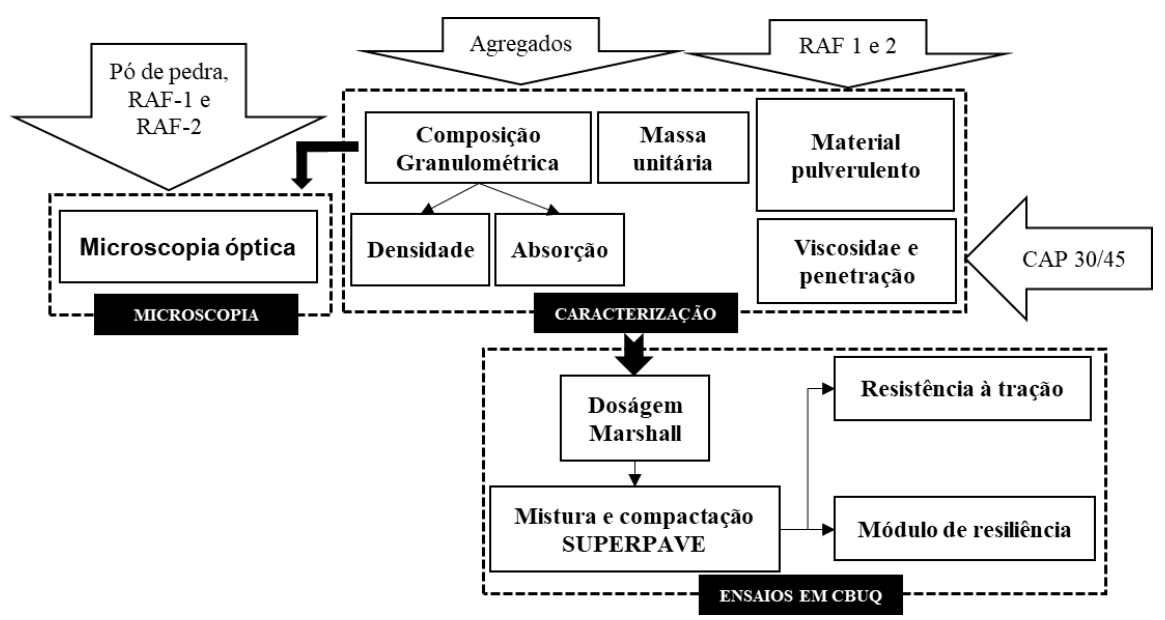

Figura 4: Fluxograma da execução de ensaios de caracterização, microscopia e ensaios mecânicos de concreto asfáltico.

Tabela 3: Ensaios realizados de acordo com a norma de método de ensaio e material utilizado.

\begin{tabular}{c|c|c|c}
\hline MATERIAIS ANALISADOS & DIÂMETRO MAXIMO DOS GRÃOS & UNIDADE & AUMENTO \\
\hline \multirow{2}{*}{ Pó de pedra, RAF 1 e 2 } & 6,35 & $\mathrm{~mm}$ & 10 e 40 vezes \\
\cline { 2 - 4 } & 0,159 & $\mathrm{~mm}$ & 10 e 40 vezes \\
\hline
\end{tabular}

As misturas de CBUQ foram preparadas utilizando a composição granulométrica das misturas de agregados e RAFs determinada pela especificação técnica do Departamento de Estradas e Rodagem (DER) ET-DE-P00:027/2005 [43]. Os materiais utilizados: agregados minerais, filler, RAF-1 e RAF-2 foram ajustados nas proporções em peso de modo a atender os critérios da Faixa III e as taxas de substituições em peso em relação ao pó de pedra pelo RAF 1 ou 2, de acordo com a tabela 4, que também contempla a terminologia de cada mistura. Ja a dosagem de CAP 30/45 para cada mistura, foi determinada pelo método Marshall [38], fixando o volume de vazios de cada mistura em $4 \%$.

Tabela 4: Ensaios realizados de acordo com a norma de método de ensaio e material utilizado.

\begin{tabular}{c|c|c}
\hline \multirow{2}{*}{ TERMINOLOGIA DAS MISTURAS } & \multicolumn{2}{|c}{ SUBSTITUIÇÃO EM PESO } \\
\cline { 2 - 3 } & RAF-1 & RAF-2 \\
\hline $50-\mathrm{M}-1$ & $50 \%$ & $0 \%$ \\
\hline $100-\mathrm{M}-1$ & $100 \%$ & $0 \%$ \\
\hline $50-\mathrm{M}-2$ & $0 \%$ & $50 \%$ \\
\hline $100-\mathrm{M}-2$ & $0 \%$ & $100 \%$ \\
\hline Controle & $0 \%$ & $0 \%$ \\
\hline
\end{tabular}

Uma vez definidos os teores de CAP para cada mistura, estas foram preparadas novamente com o teor de projeto, utilizando o método da mistura giratória SUPERPAVE [39] por meio de uma uzina de asfalto em escala reduzida. Em seguida, os CPs foram compactados pelo método giratório SUPERPAVE; equipamentos ilustrados na figura 5. Uma vez obtidos todos CPs (3 exemplares para cada mistura e ensaio), estes foram testados em ensaios de tração por compressão diametral e módulo de resiliência de acordo com os procedi- 
mentos específicos [41,42].

\section{RESULTADOS E DISCUSSÕES}

\subsection{Caracterização dos agregados minerais, RAFs, filler e ligante asfáltico}

As frações em peso de material passante na peneira de abertura de 0,075 mm para os materiais: brita 1 , brita 0, pó de pedra, RAF 1 e 2 foram obtidas. Os resultados são apresentados no gráfico de barras da figura 5 . Estes resultados mostram que os resíduos estão dentro do critério estabelecido pela norma brasileira de agregados [20], permanecendo com taxas abaixo dos $11 \%$ determinados pela norma como teor limite.

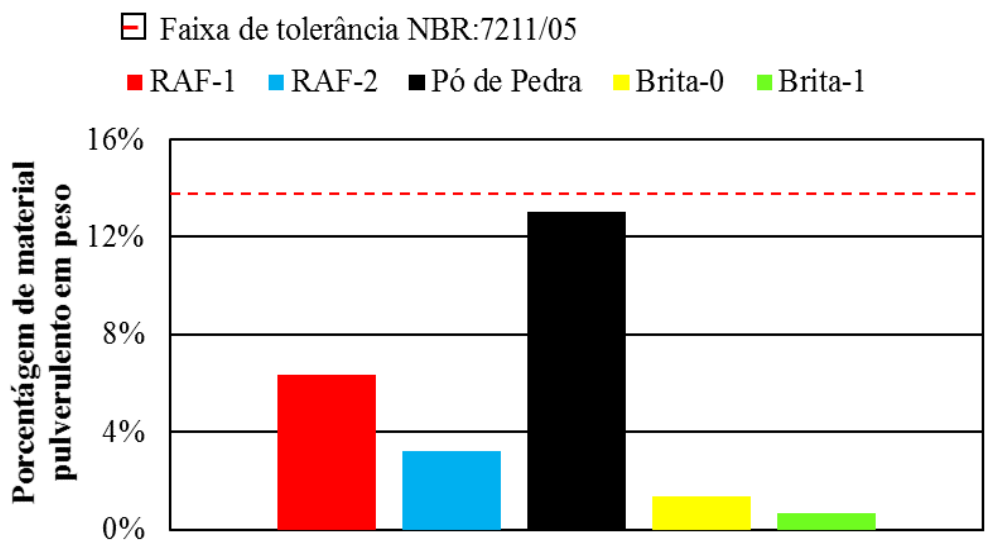

Figura 5: Gráfico de barras dos resultados em do material pulverulento presente em massa.

O gráfico da figura 6 mostra que a composição granulométrica do RAF é similar ao pó de pedra com suas composições dentro dos limites estabelecidos pela norma brasileira [20] para agregados miúdos. Já os demais materiais analisados, brita 0 e 1, permaneceram dentro dos limites de classificação comercial definidos pela norma brasileira ABNT-NBR:7225/1993 [44].

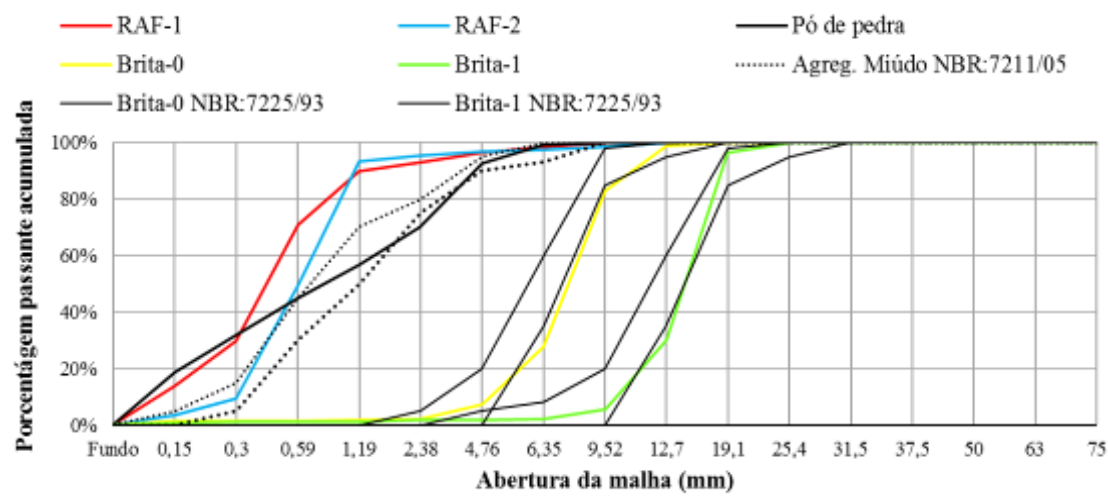

Figura 6: Gráfico da composição granulométrica dos agregados e RAF.

Estes resultados permitiram a formulação das misturas de agregados, filler e RAFs segundo os critérios granulométricos da Faixa III [43], o grafico da figura 7 apresenta a composição granulométrica de todas as misturas utilizadas, delimitadas pelos critérios da Faixa III. 


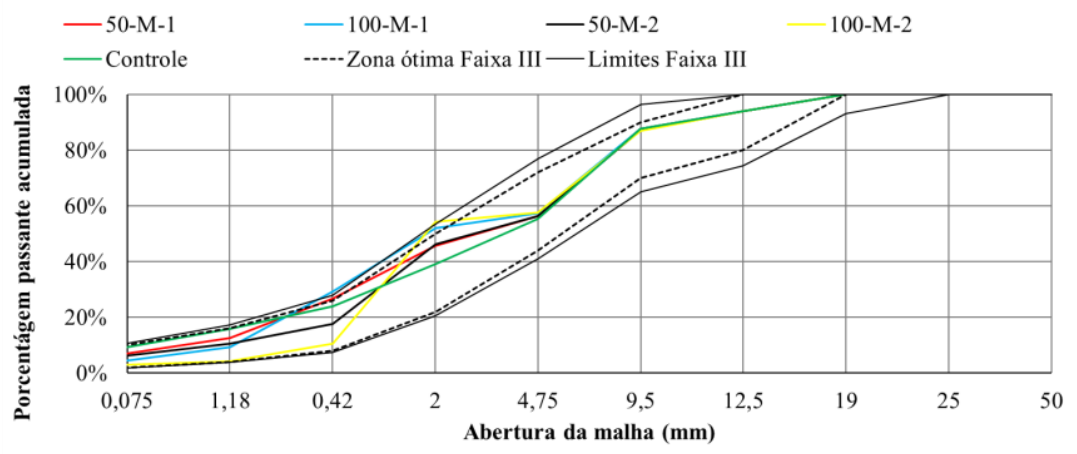

Figura 7: Gráfico da composição granulométrica das misturas de agregados e RAF nos limites da Faixa III [43].

Os resultados preliminares de caracterização mostraram grande semelhança física entre os resíduos de areia de fundição (tanto do aterro quanto diretamente da indústrias) e o agregado mineral convencional, além de estarem dentro dos critérios da norma de agregados [20]. A tabela 5 apresenta os resultados dos demais ensaios de caracterização realizados. Ja a figura 8 apresenta os resultados da caracterização do ligante, mostrando que o mesmo permanece dentro da estabilidade $30 / 45$ prevista pelo fabricante.

Tabela 5: Resultados dos demais ensaio de caracterização em agregados, RAFs e filler.

\begin{tabular}{l|c|c|c|c|c|c}
\hline \multirow{2}{*}{ PROPRIEDADE } & \multicolumn{7}{c}{ AGREGADO / RESÍ́UO / FILLER } \\
\cline { 2 - 7 } & RAF-1 & RAF-2 & PÓ DE PEDRA & BRITA-0 & BRITA-1 & FILLER \\
\hline Massa unitária $\left(\mathrm{kg} / \mathrm{m}^{3}\right)$ & 1398 & 1312 & 1652 & 1720 & 1910 & - \\
\hline Densidade real $\left(\mathrm{g} / \mathrm{cm}^{3}\right)$ & 2,72 & 2,64 & 2,86 & 2,65 & 2,72 & 2,00 \\
\hline Densidade aparente $\left(\mathrm{g} / \mathrm{cm}^{3}\right)$ & 1,87 & 2,07 & 2,33 & - & - & - \\
\hline Densidade SSS $\left(\mathrm{g} / \mathrm{cm}^{3}\right)$ & 2,01 & 2,17 & 2,37 & - & - & - \\
\hline Absorção de água $(\%)$ & 1,61 & 2,52 & 0,64 & 0,56 & 0,54 & - \\
\hline
\end{tabular}

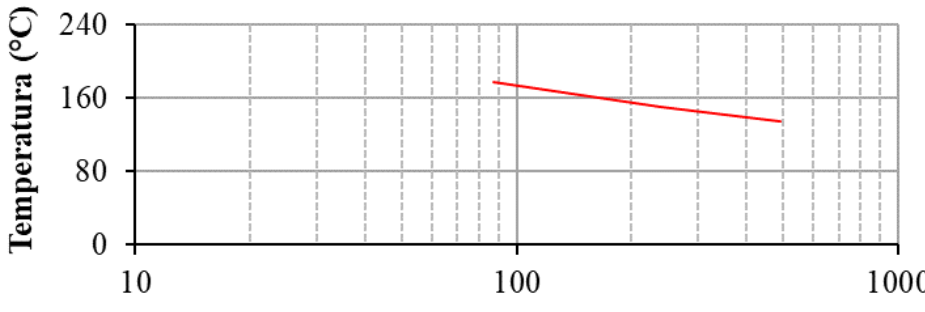

Viscosidade Brookfield $\left(\mathrm{mm}^{2} / \mathrm{s}\right)$

\begin{tabular}{lcc}
\hline Parametetro & Max & Min \\
\hline Temperatura de mistura $\left(\mathrm{C}^{\circ}\right):$ & 162 & 156 \\
Temperatura de compactação $\left(\mathrm{C}^{\circ}\right):$ & 150 & 145 \\
Viscosidade Brookfield da mistura $\left(\mathrm{mm}^{2} / \mathrm{s}\right):$ & 95 & 458 \\
Viscosidade Brookfield de compactação $\left(\mathrm{mm}^{2} / \mathrm{s}\right):$ & 231 & 103
\end{tabular}

Figura 8: Resultados dos ensaios de caracterização do ligante asfáltico CAP 30/45. 


\subsection{Microscopia óptica}

Imagens ampliadas nos aumentos de 10 e 40 vezes foram feitas utilizando estereoscópio. Estas ampliações, apresentadas na figura 9 para o aumento de 10 vezes e figura 10 para o aumento de 40 vezes revelam a uniformidade entre as partículas do RAF e semelhança morfológica às partículas do pó de pedra.

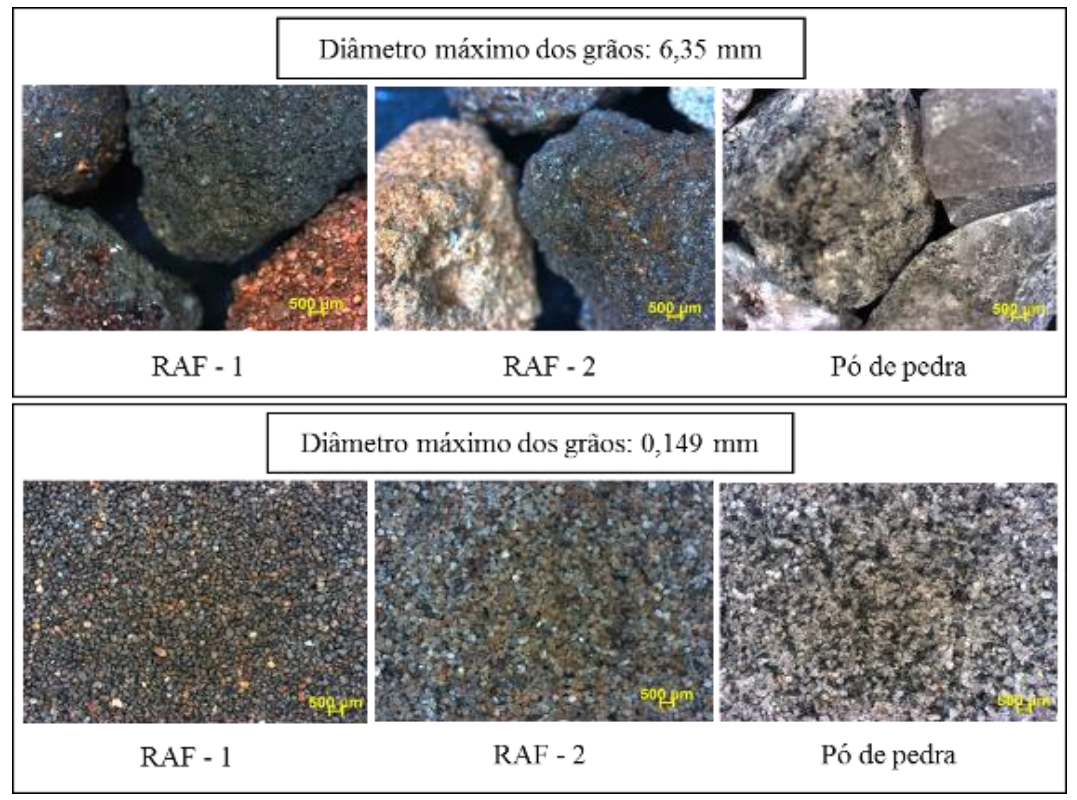

Figura 9: Imagens ampliadas de 10 vezes do pó de pedra e RAF.

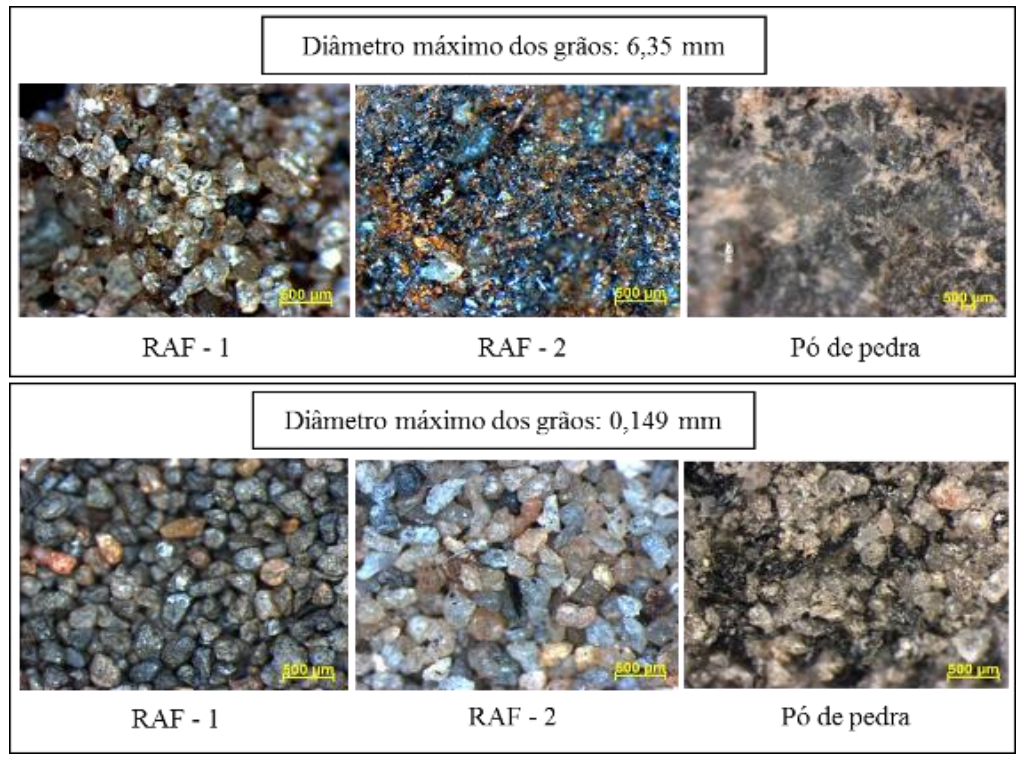

Figura 10: Imagens ampliadas de 40 vezes do pó de pedra e RAFs em um estereoscópio óptico.

\subsection{Ensaios em concreto asfáltico}

De posse dos resultados de caracterização, foram projetadas as misturas asfálticas para a realização da dosagem Marshall [38]. Esta etapa deste presente artigo foi realizada integralmente de forma manual, onde foi fixado o valor de $4 \%$ de volume da vazios (Vv) para determinar o teor ótimo de asfalto de cada mistura. Desta forma, como pode ser observado nos gráficos da figura 11, a mistura 50-RAF-1 obteve um teor muito próximo ao Controle (4,8\%), ja as misturas 100-ADF-1 e 50-ADF-2 necessitaram de quantidades maiores de CAP 30/45 para atingir um Vv de $4 \%$ e a mistura 100-ADF-2 não atingiu um Vv de $4 \%$ durante a dosagem, opatando-se em fixa-lo em 7\%. Nestes gráficos são apresentados os valores obtidos da variação de densidade Rice [39], densidade aparente da mistura de agregados (Gmb), resistência à tração [41], Vv, vazios cheios de 
betume (VCB) [39] e vazios do agregado mineral (VAM) em função do teor de ligante durante o Marshall para todas as misturas.

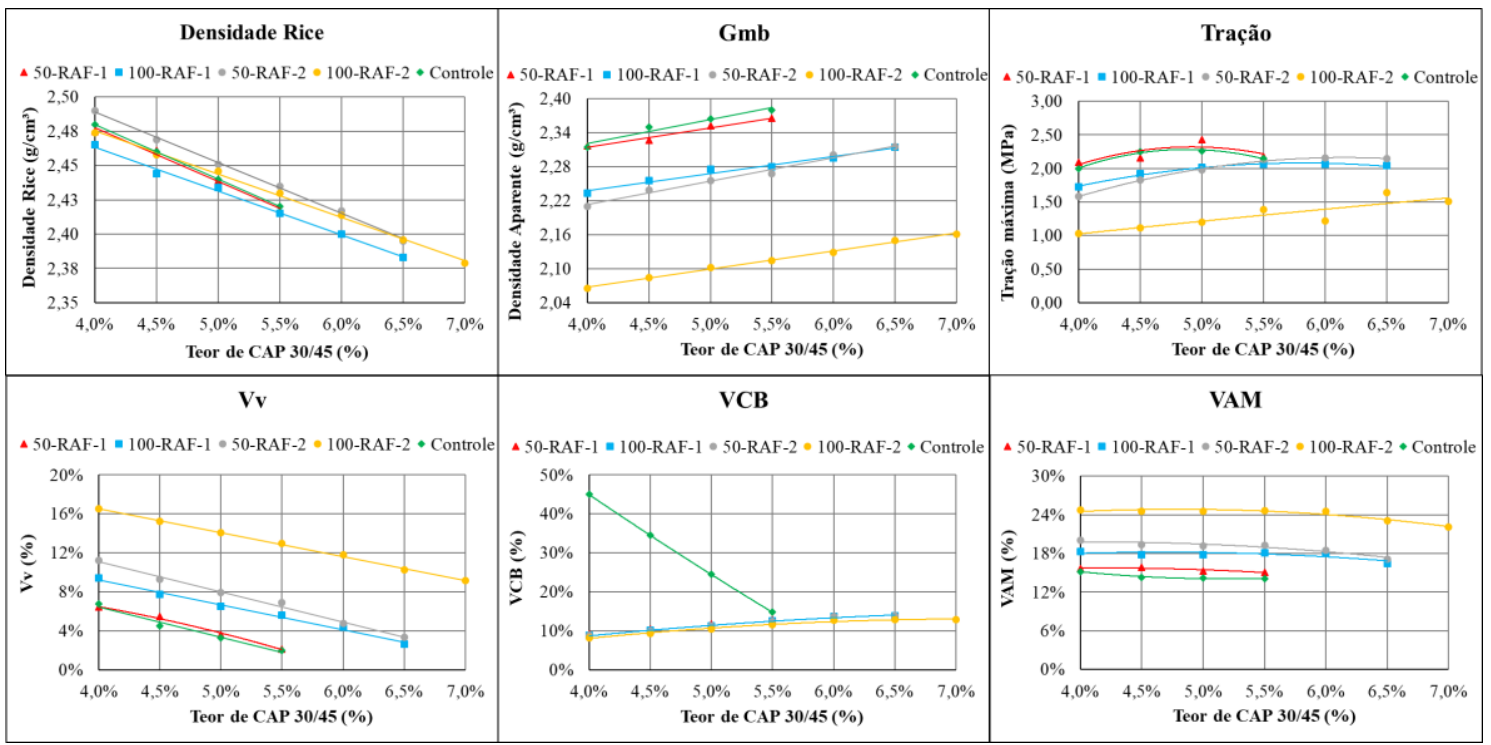

Figura 11: Graficos das principais propriedades físicas das misturas de agregados e CBUQs durante a dosagem Marshall.

As misturas asfálticas, de acordo com suas composições e terminologias descritas pela tabela 4 foram preparadas [38] e compactadas [39] pelo método giratório SUPERPAVE, produzindo 3 CPs para cada mistura e cada ensaio. A tabela 6 apresenta as propriedades físicas das misturas com teor de projeto e as figuras 12 e 13 ilustram estes procedimentos.

Tabela 6: Principais propriedades físicas das misturas com teor ótimo de asfalto e as dimensões dos CPs.

\begin{tabular}{|c|c|c|c|c|c|}
\hline \multirow[t]{2}{*}{ PROPRIEDADE } & \multicolumn{5}{|c|}{ CONCRETO ASFÁLTICO } \\
\hline & 50-RAF-1 & 100-RAF-1 & 50-RAF-2 & 100-RAF-2 & CONTROLE \\
\hline Teor ótimo de asfalto (\%) & 4,8 & 5,9 & 6,2 & 7 & 4,7 \\
\hline Teor ótimo de asfalto efetivo após $2 \mathrm{~h}(\%)$ & 4,6 & 5,9 & 5,9 & 7 & 4,4 \\
\hline Absoção de asfalto pelo agregado (\%) & 0,2 & 0 & 0,3 & 0 & 0,3 \\
\hline Razão betume vazios RBV (\%) & 71,9 & 75,9 & 77,3 & 63,7 & 72,1 \\
\hline $\mathrm{Vv}(\%)$ & 4,2 & 4,3 & 4 & 8,6 & 4 \\
\hline $\operatorname{VCB}(\%)$ & 11,7 & 14,1 & 14,9 & 16,5 & 11,4 \\
\hline $\operatorname{VAM}(\%)$ & 15 & 18 & 17,5 & 23,8 & 14,2 \\
\hline Densidade aparente SSS $\left(\mathrm{g} / \mathrm{cm}^{3}\right)$ & 2,62 & 2,63 & 2,63 & 2,64 & 2,62 \\
\hline Densidade efetiva $\left(\mathrm{g} / \mathrm{cm}^{3}\right)$ & 2,64 & 2,62 & 2,65 & 2,64 & 2,64 \\
\hline Densidade Rice (g/cm³) & 2,34 & 2,29 & 2,31 & 2,16 & 2,36 \\
\hline Densidade máxima teórica $\left(\mathrm{g} / \mathrm{cm}^{3}\right)$ & 2,45 & 2,39 & 2,41 & 2,71 & 2,46 \\
\hline Altura média dos CPs (mm) & 66,69 & 67,93 & 67,18 & 71,23 & 65,8 \\
\hline Diâmetro dos CPs (mm) & 100 & 100 & 100 & 100 & 100 \\
\hline
\end{tabular}



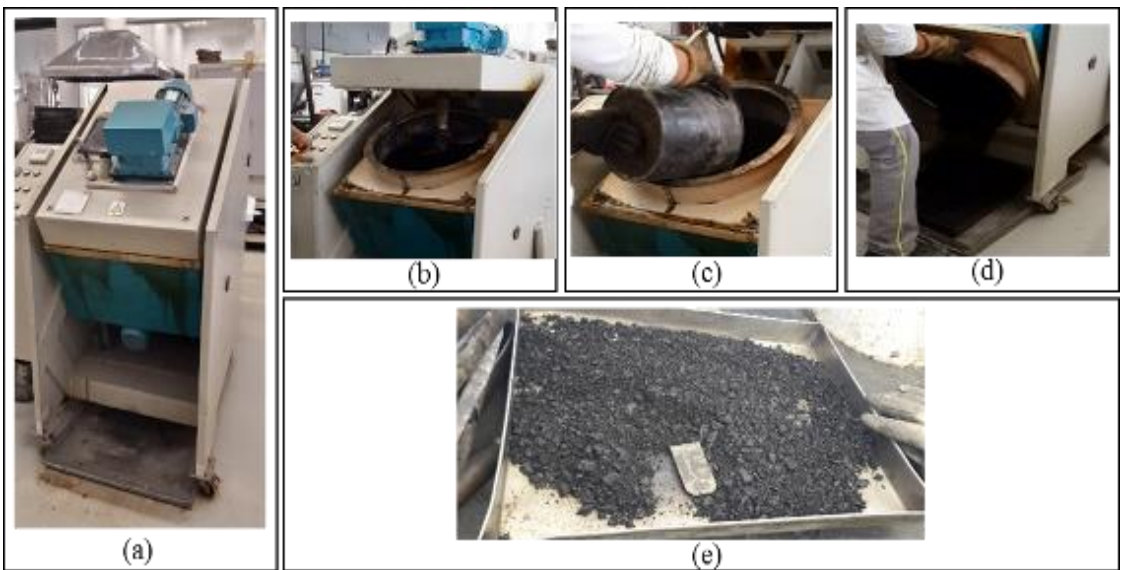

Figura 12: Fotografias do preparo das massas asfálticas de projeto, onde em (a) a usina asfáltica em tamanho reduzido está em destaque, em (b) a abertura do equipamento é acionada, em (c) a mistura de agrgados é inserida no tambor do equipamento, em (d) a mistura asfáltica pronta é despejada na bandeja (e).

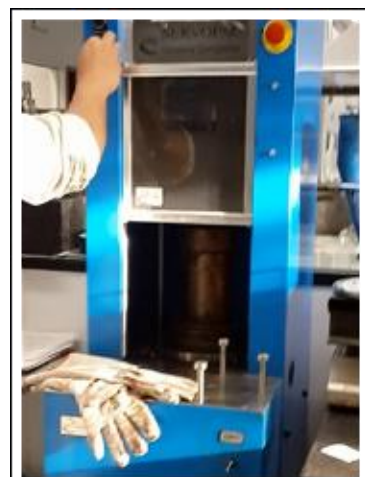

(a)

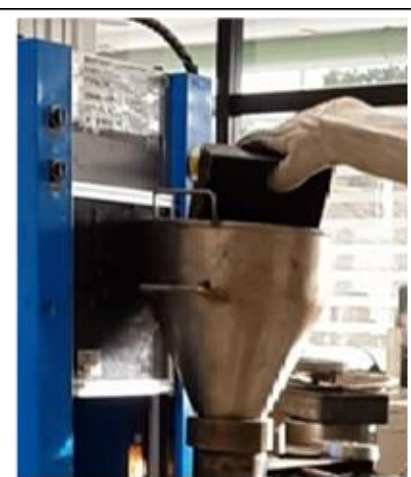

(b)

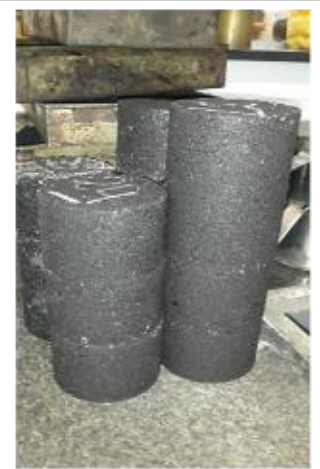

(c)

Figura 13: Fotografias da compactação giratória dos CPs, onde em (a) o equipamento é acionado, em (b) a mistura asfáltica é inserida e em (c) os CPs obtidos.

Os CPs produzidos foram testados a temperatura ambiente de $20^{\circ} \mathrm{C}$ e obtidos os módulos de resistência a tração por compressão diametral, em MPa de acordo com os equipamentos e procedimentos determinados pela norma [41]. Da mesma forma, outros CPs com as mesmas formulações foram testados no ensaio de módulo de resiliência à $20^{\circ} \mathrm{C}$, de acordo com os equipamentos e métodos determinados pela norma [42]; neste caso o módulo de Poisson adotado foi de $\alpha=0,3$. Os resultados mostraram pequenas variações de resistência entre massas asfálticas contendo resíduos e a mistura de controle com módulos de resistencia acima do mínimo recomendado pela norma de engenharia rodoviária, determinada pela Especificação de Serviço do Departamento Nacional de Infraestrutura de Transporte, a DNIT-ES:031/2006 [38]. As figuras 14 e 15 apresentam os gráficos de barras dos resultados obtidos nestes ensaios.

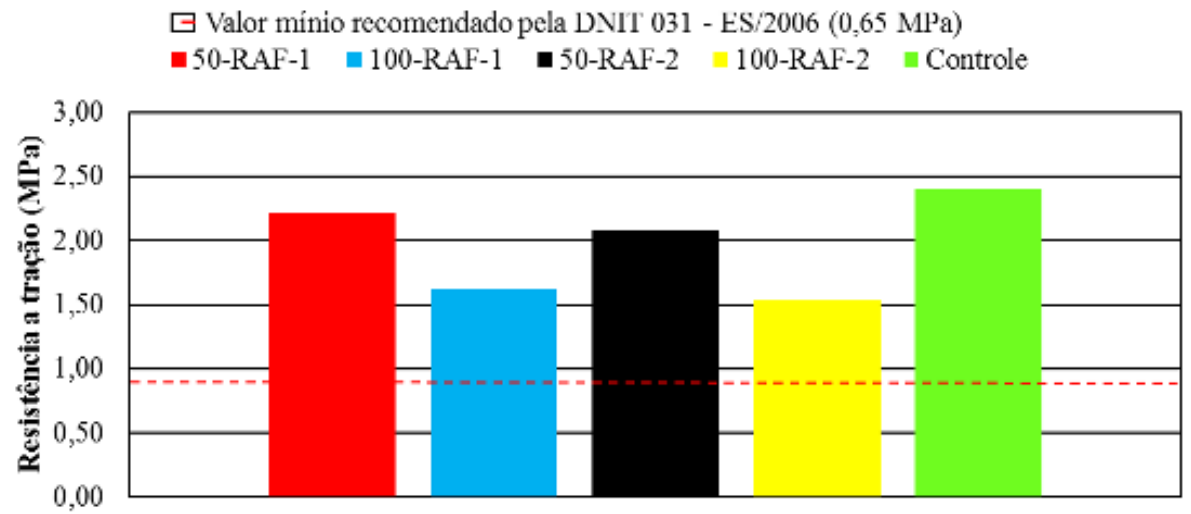


Figura 14: Gráfico de barras da resistência a tração por compressão diametral em MPa.

Os resultados aqui obtidos, mostram potencial viabilidade técnica do emprego de RAF como agregado em concretos asfálticos. No que diz respeito às características dos resíduos, estes se mostraram muito parecidos com o agregado mineral convencional, já os ensaios específicos de concreto asfáltico, apresentaram resultados muito condizentes com a especificação de Engenharia Rodoviária.

Na literatura atual e dos últimos 20 anos de pesquisa do emprego de RAF na construção civil, são observados resultados obtidos que corroboram as afirmações feitas neste presente artigo. $\mathrm{O}$ gráfico da figura 16 e a tabela 7 mostram estas comparações acerca da caracterização do RAF por diferentes autores, sendo o resíduo originário de escavações em aterros sanitários (identificado como RAF-1) ou diretamente das indústrias (identificado como RAF-2).

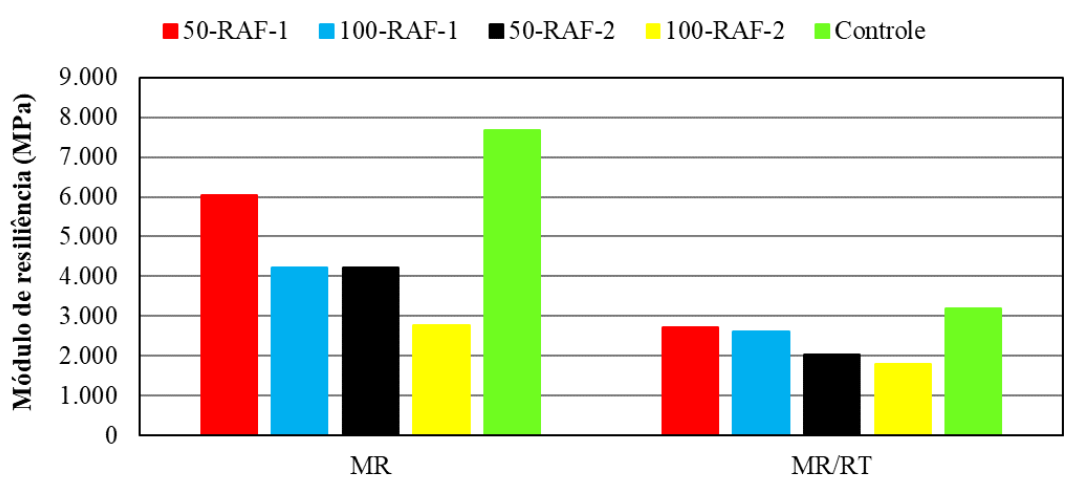

Figura 15: Gráfico de barras do módulo de resiliência em MPa e razão módulo de resiliência e resistência à tração $(\mathrm{MR} / \mathrm{RT})$.

Tabela 7: Principais características físicas do RAF obtidas por diferentes autores.

\begin{tabular}{l|c|c|c|c|c|c|c}
\hline \multirow{2}{*}{ PROPRIEDADE } & \multicolumn{2}{|c|}{ OBTIDO } & \multicolumn{5}{c}{ ORGIGEM DO RAF : AUTOR } \\
\cline { 2 - 9 } & RAF-1 & RAF-2 & RAF-2 : [5] & RAF-2 : [9] & RAF-2 : [19] & RAF-2 : [21] & RAF-1 : [22] \\
\hline Mat. Pulverulento $(\%)$ & 6,35 & 3,22 & 8,7 & 6,1 & 13,6 & 8 & - \\
\hline Massa unitária $\left(\mathrm{kg} / \mathrm{m}^{3}\right)$ & 1398 & 1312 & - & - & 1115 & - & 2583 \\
\hline Densidade real $\left(\mathrm{g} / \mathrm{cm}^{3}\right)$ & 2,72 & 2,64 & 2,56 & 2,65 & 2,13 & 2,18 & 2,47 \\
\hline Absorção de água $(\%)$ & 1,61 & 2,52 & 0,64 & 3 & - & 0,42 & 0,43 \\
\hline
\end{tabular}

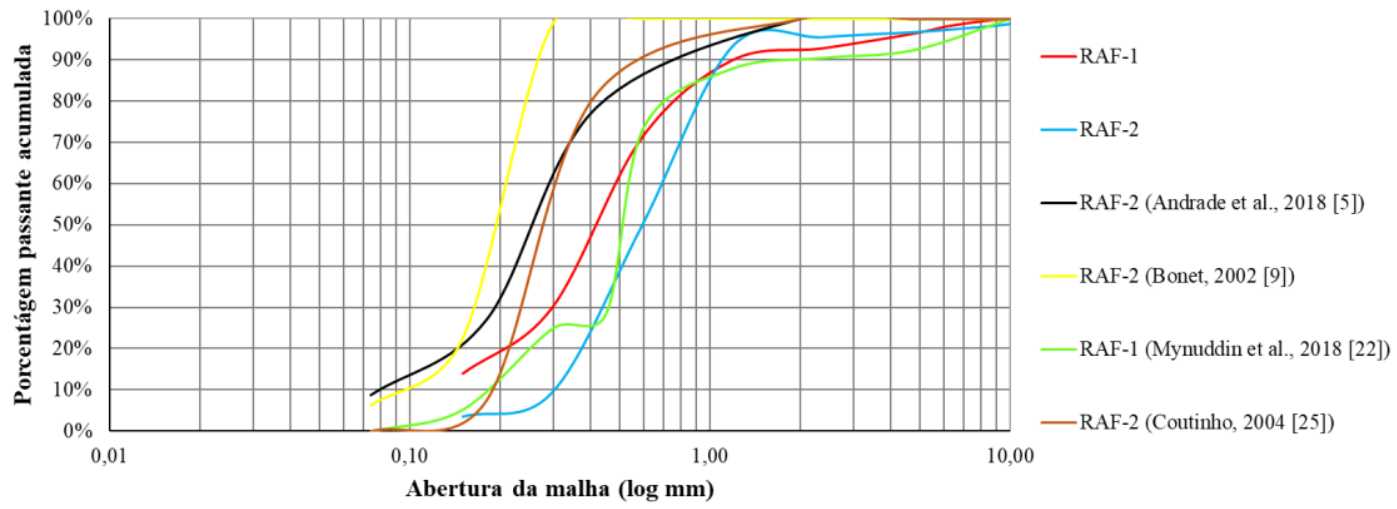


Figura 16: Composição granulométrica obtida por diferentes autores do RAF 1 e 2.

Desta pesquisa na literatura, foram encontrados estudos com o emprego do RAF em CBUQ, produzindo a tabela 8 que apresenta os resultados destes ensaios específicos. Estes números são muito próximos aos enconrados neste presente artigo tanto referente às principais características das misturas asfálticas quanto às propriedades mecânicas destas.

Tabela 8: Principais características das misturas, segundo diferentes autores.

\begin{tabular}{|c|c|c|c|c|c|c|}
\hline \multirow{3}{*}{ PROPRIEDADE } & \multicolumn{6}{|c|}{ CONCRETO ASFÁLTICO } \\
\hline & \multicolumn{4}{|c|}{ OBTIDO } & \multirow{2}{*}{$\begin{array}{c}\text { M1 } \\
\text { RAF-2 [25] }\end{array}$} & \multirow{2}{*}{$\begin{array}{c}\text { M2 } \\
\text { RAF-1 [44] }\end{array}$} \\
\hline & 50-RAF-1 & 100-RAF-1 & RAF-2 [44] & 100-RAF-2 & & \\
\hline Teor ótimo de asfalto (\%) & 4,8 & 5,9 & 6,2 & 7 & 6 & 5,35 \\
\hline $\operatorname{RBV}(\%)$ & 71,9 & 75,9 & 77,3 & 63,7 & 78 & 77 \\
\hline $\mathrm{Vv}(\%)$ & 4,2 & 4,3 & 4 & 8,6 & 4 & 4 \\
\hline VAM (\%) & 15 & 18 & 17,5 & 23,8 & 18,59 & 18,4 \\
\hline Densidade aparente $\left(\mathrm{g} / \mathrm{cm}^{3}\right)$ & 2,62 & 2,63 & 2,63 & 2,64 & 2,48 & 2,7 \\
\hline Tração (MPa) & 2,21 & 1,62 & 2,08 & 1,53 & 1,34 & 1,07 \\
\hline Modulo de resiliência (MPa) & 6040 & 4228 & 4209 & 2774 & 6700 & 5700 \\
\hline $\mathrm{MR} / \mathrm{RT}$ & 2731 & 2602 & 2027 & 1809 & 5000 & 5327 \\
\hline M1: & \multicolumn{6}{|c|}{ CBUQ com CAP 20, Faixa III com substituição de $15 \%$ do pó de pedra por RAF-2 } \\
\hline M2: & \multicolumn{6}{|c|}{ CBUQ com CAP 50/60, Faixa III com substituição de $60 \%$ do pó de pedra por RAF-1 } \\
\hline
\end{tabular}

\section{CONCLUSÕES}

Destes resultados empiricamente obtidos, as seguintes conclusões foram tomadas:

- Caracterização: o teor de material pulverulento, composição granulométrica e as demais características físicas dos resíduos de areia de fundição se mostraram muito semelhantes ao pó de pedra, agregado amplamente utilizado na pavimentação asfáltica flexível e em acordo com os critérios da norma brasileira para agregados minerais [20];

- Microscopia: as imagens ampliadas revelaram uniformidade entre os grãos dos resíduos e semelhantes ao pó de pedra em relação a morfologia;

- Concreto asfáltico: no caso do ensaio de resistência à tração por compressão diametral, os CPs contendo RAF obtiveram perdas muito pequenas em relação à mistura controle e com módulos de resistência acima dos critérios estabelecidos pela especificação do Departamento Nacional de Infraestrutura de Transportes [38]. Para o ensaio de módulo de resiliência, esta diferença entre resultados se mostrou analoga, principalmente para a mistura 50-RAF-1 que foi a que apresentou o melhor desempenho em ensaios mecânciso.

- Comaparações: em relação aos resultados da literatura pesquisada, as características do RAF e das misturas mostraram resultados muito próximos entre si. Entretanto nos ensaios mecânicos notaramse pequenas diferenças.

Assim sendo, fica determinado que a utilização de RAF, sendo de aterros sanitários ou diretamente de indústrias de fundição, apresenta viabilidade técnica em obras de pavimentação flexível, outrora grandes consumidoras de agregados minerais, suscitando a sustentabilidade neste setor da construção civil; visto que também, os descartes adequado ou inadequado do resíduo demandam enormes custos financeiros e socioambientais.

Portanto o reuso de RAF como agregado gera benefícios como a redução do custo de construção de rodovias, redução da utilização de recursos minerais esgotáveis, redução dos gastos por parte de indústrias siderúrgicas para aterrar seus principais resíduos, redução de impactos socioambientais quando este resíduo é descartado de forma ilegal, aumento da geração de recursos financeiros por parte das empresas administradoras de aterros sanitários que podem requerer seus espaços para aterramento de resíduos "mais valiosos" como resíduos perigosos Classe I, aumento da vida útil dos aterros sanitários já operantes e a redução da demando por novos espaços licitados para atuarem como aterros sanitários industriais. 


\section{AGRADECIMENTOS}

Os agredecimentos da realização e apoio a presente pesquisa vão para agência CAPES, pelo financiamento, àos laboratórios do Instituto de Estudos Avançado IEAv e do Instituto Tecnológico de Aeronáutica ITA (São José dos Campos/São Paulo), pelo auxílio nos ensaios de caracterização de agregados e RAF e ensaios de microscopia óptica, ao Centro de Pesquisas Rodoviárias da Concessionária CCR Nova Dutra, pela realização de todos os ensaios específicos de concreto asfáltico e à empresa Essencis Ecossistema LTDA. pelo fornecimento de todos RAF utilizado nesta pesquisa.

\section{BIBLIOGRAFIA}

[1] CAVALCANTI, C., FURTADO, A., STAHEL, A., et al., Desenvolvimento e natureza: Estudos para uma sociedade sustentável, In: INPSO/FUNDAJ, Instituto de Pesquisas Sociais, Fundação Joaquim Nabuco, Ministerio de Educacao, Governo Federal, Recife, Brasil, p. 262, Octubre 1994.

[2] CORREA, L.R., Sustentabilidade na construção civil, Monografia, UFMG, Belo Horizonte, MG, Brasil, 2009.

[3] UBIRATAN, F., "Cidades sustentáveis e a Engenharia Urbano-Industrial”, In: Anais da 61 ${ }^{a}$ SOEAA Semana Oficial da Engenharia, Arquitetura e da Agronomia, pp. 59-69, São Luís, Maranhão, Brasil, Nov./Dez. 2004.

[4] BINA, P., "Metodologia de Utilização de Rejeitos Industriais na Pavimentação: Estudo de Caso de Uso de Areia de Fundição”, Dissertação de M.Sc., IPT/SP, São Paulo, SP, Brasil, 2002.

[5] ANDRADE, L.B., CARNIN, R.L.P., PINTO, R.C.A., "Areia descartada de fundição para uso em concreto de cimento Portland: análise do agregado”, Revista Matéria, v. 23, n. 3, Out. 2018.

[6] KURZ, M. N., BRANDELLI, T. M.., PALIGA, C. M., et al., "A potencialidade do uso de resíduo de borracha de pneu em argamassa: análise das propriedades físicas e mecânicas", Revista Matéria, v. 23, n. 3, Dez. 2018.

[7] COSTA, K., GUIMARÃES, A.C.R., REIS, M.M., et al., “A Estudo do processo de lixiviação controlada da escória de aciaria em extrator soxhlet visando emprego em pavimentos", Revista Matéria, v. 22, n. 2 , Nov. 2017.

[8] The Casting Development Centre. BENEFICIAL RE-USE OF FOUNDRY BY-PRODUCTSBENEFICIAL RE-USE FOR MANAGERS MANUAL, http://www.castingstechnology.com/public/services/environmenthealthandsafety/EHSBeneficialReuseofFoundryBy-products.asp. Acessado em novembro de 2018.

[9] BONET, I., "Valorização do resíduo areia de fundição (RAF). Incorporação nas massas asfálticas do tipo CBUQ”, Dissertação de M.Lc., UFSC, Florianópolis, SC, Brasil, 2002.

[10] Conselho Brasileiro de Construção Sustentável, CBCS, http://www.cbcs.org.br/website/. Acessado em novembro de 2018.

[11] Associação Brasileira de Fundição. ÍNDICES SETORIAIS DE 2018, http://www.abifa.org.br/indicessetoriais/. Acessado em dezembro de 2018

[12] KMITA, A., FISCHER, C., HODOR, K., et al., "Thermal decomposition of foundry resins: a determination of organic products by thermogravimetry-gas chromatography-mass spectrometry (TG-GC-MS)", Arabian Journal of Chemistry, n. 11, pp. 380-387, 2018.

[13] STANCLIFFE, M., "Phenolic urethane binders cold-box binders - A study of global properties, variables, causes and effects", In: Anais do World Foundry Congress: Casting the Future (WFC '06), WFC 2006, pp. 118-128, Harrogate, Inglaterra, 5-7 Junho 2006.

[14] HOLTZER M., DAŃKO, R., "Molds and Cores Systems in Foundry". In: The Author(s) 2015 editors, Microstructure and properties of ductile iron and compacted graphite iron castings, 1 ed., capítulo 2, Springer briefs in Materials, 2015. 
[15] ZHANG, B., GARRO, M., CHAUTARD, D., et al., "Gas Evolution from Resin-Bonded Sand Cores Prepared by Various Processes", Metallurgical Science and Technology. pp. 27-32, 2002.

[16] OWUSU, Y.A., "Physical-chemistry study of sodium silicate as a foundry sand binder", Advances in Colloid and Interface Science, pp. 57-91, 1982.

[17] DECISÃO DE DIRETORIA (2007), $n^{\circ}$ 152/2007/C/E de 08/08/2007: Dispõe sobre procedimentos para gerenciamento de areia de fundição, 2007. São Paulo, Companhia Ambiental do Estado de São Paulo - CETESB.

[18] ANÔNIMO (2004), NBR-10004: Resíduos sólidos: classificação. Rio de Janeiro, ABNT - Associação Brasileira de Normas Técnicas.

[19] BONIN, A.L., ROSSINI, A.J., ZABIM, A.F.P., "Reutilização da areia preta de fundição na construção civil", In: Anais da Feira de Fundidos, Insumos e Equipamentos, FENAF 95 Congresso de Fundição CONAF 95 ABIFA, pp. 203-221, 1995.

[20] ANÔNIMO (2005), NBR-7211: Agregados para concreto - especificações. Rio de Janeiro, ABNT Associação Brasileira de Normas Técnicas.

[21] SINGH, G., SIDDIQUE, R., "Effect of waste foundry sand (WFS) as partial replacement of sand on the strength, ultrasonic pulse velocity and permeability of concrete", Construction and Building Materials, v. 26, n. 1, pp. 416-422, 2012.

[22] MYNUDDIN, S.A., MOHAN, M., REDDY, T.I., et al., "Strength behavior of concrete produced with foundry sand as fine aggregate replacement", International Journal of Modern Trends in Engineering and Science, v. 5, n. 8, pp. 3476-3480, 2018.

[23] YAZOGHLI-MARZOUK, O., GREULLET, N.V., CANTEGRIT, L., et al., "Recycling foundry sand in road construction-field assessment", Journal of Construction and Building Materials, v. 61, pp. 69-78, 2014.

[24] KLINSKY, L.M.G., "Avaliação do reaproveitamento de areia de fundição residual em camadas de pavimento”, Tese de D.Lc., EESC/USP, São Carlos, SP, Brasil, 2013.

[25] COUTINHO NETO, B., "Avaliação do reaproveitamento de areia de fundição como agregado em misturas asfálticas densas", Tese de D.Lc., EESC/USP, São Carlos, SP, Brasil, 2004.

[26] ANÔNIMO (2004), NBR-10007: Amostragem de resíduos sólidos. Rio de Janeiro, ABNT - Associação Brasileira de Normas Técnicas.

[27] ANÔNIMO (2001), NM-26: Agregados: amostragem. Rio de Janeiro, ABNT - Associação Brasileira de Normas Técnicas.

[28] ANÔNIMO (2001), NM-27: Agregados: redução de amostras para ensaios em laboratório. Rio de Janeiro, ABNT - Associação Brasileira de Normas Técnicas.

[29] ANÔNIMO (2003), NM-46: Agregados - determinação do material fino que passa através da peneira $75 \mu m$, por lavagem. Rio de Janeiro, ABNT - Associação Brasileira de Normas Técnicas.

[30] ANÔNIMO (2003), NM-248: Agregados: determinação da composição granulométrica. Rio de Janeiro, ABNT - Associação Brasileira de Normas Técnicas.

[31] ANÔNIMO (2006), NM-45: Agregados: determinação da massa unitária e do volume de vazios. Rio de Janeiro, ABNT - Associação Brasileira de Normas Técnicas.

[32] ANÔNIMO (2003), NM-52: Agregado miúdo: determinação da massa específica e massa específica aparente. Rio de Janeiro, ABNT - Associação Brasileira de Normas Técnicas.

[33] ANÔNIMO (2003), NM-53: Agregado graúdo: determinação de massa específica, massa específica aparente e absorção de água. Rio de Janeiro, ABNT - Associação Brasileira de Normas Técnicas.

[34] ANÔNIMO (2001), NM-23: Cimento portland e outros materiais em pó: determinação da massa específica. Rio de Janeiro, ABNT - Associação Brasileira de Normas Técnicas.

[35] ANÔNIMO (2001), NM-30: Agregado miúdo: determinação damabsorção de água. Rio de Janeiro, ABNT - Associação Brasileira de Normas Técnicas.

[36] ANÔNIMO (2014), NBR-14541: Lubrificantes: determinação da viscosidade a baixa temperatura com o viscosímetro Brookfield. Rio de Janeiro, ABNT - Associação Brasileira de Normas Técnicas.

[37] ANÔNIMO (2010), ME-155: Método de ensaio. Material asfáltico: determinação da penetração. Rio de Janeiro, DNIT - Departamento Nacional de Infraestrutura de Transporte. 
[38] ANÔNIMO (2006), ES-031: Especificação de serviço. Pavimentos flexíveis: concreto asfáltico. Rio de Janeiro, DNIT - Departamento Nacional de Infraestrutura de Transporte.

[39] ANÔNIMO (2011), D-2041/D-2041M: Standard test method for theoretical maximum specific gravity and density of bituminous paving mixtures. West Conshohocken, PA - ASTM International.

[40] ANÔNIMO (2016), PP-60: Standard practice for preparation of cylindrical performance test specimens using the SUPERPAVE gyratory compactor (SGC). Washington, AASHTO - American Association of State and Highway Transportation Officials.

[41] ANÔNIMO (2017), ME-136: Método de ensaio. Pavimentação asfáltica: misturas asfálticas: determinação da resistência à tração por compressão diametral. Rio de Janeiro, DNIT - Departamento Nacional de Infraestrutura de Transporte.

[42] ANÔNIMO (2010), ME-135: Método de ensaio. Pavimentação asfáltica: misturas asfálticas: determinação do módulo de resiliência. Rio de Janeiro, DNIT - Departamento Nacional de Infraestrutura de Transporte.

[43] ANÔNIMO (2005), ET-DE-P00/27: Especificação técnica. Concreto asfáltico. São Paulo, DERSA Desenvolvimento Rodoviário S.A.

[44] ANÔNIMO (1993), NBR-7225: Materiais de pedra e agregados naturais Rio de Janeiro, ABNT - Associação Brasileira de Normas Técnicas.

[45] WESSELING, D., H., "Estudo do comportamento mecânico de misturas em concreto asfáltico com incorporação de resíduos industriais”, Dissertação de M.Lc., UFRGS/PPGEC, Porto Alegre, RS, Brasil, 2005.

\section{ORCID}

Paulo Paiva Oliveira Leite Dyer Luis Miguel Gutierrez Klinsky Silvelene Alessandra Silva Maryangela Geimba de Lima https://orcid.org/0000-0001-7110-6871

https://orcid.org/0000-0002-2052-9951

https://orcid.org/0000-0003-1601-5373

https://orcid.org/0000-0002-0046-3991 